\title{
A PREVIDÊNCIA SOCIAL E O DESENVOLVIMENTO HUMANO: O CASO DO ALTO URUGUAI, RIO GRANDE DO SUL - 1988-2018
}

\author{
THE SOCIAL SECURITY AND THE HUMAN DEVELOPMENT: THE \\ CASE OF HIGH URUGUAY, RIO GRANDE DO SUL - 1988-2018
}

\section{SEGURIDAD SOCIAL Y EL DESARROLLO HUMANO: EL CASO DEL ALTO URUGUAY, RIO GRANDE DO SUL - 1988-2018}

\author{
Anacleto Zanella ${ }^{1}$ \\ https://orcid.org/0000-0002-7149-8876 \\ Humberto José da Rocha ${ }^{2}$ \\ https://orcid.org/0000-0001-9943-9125
}

Submissão: 14/10/2019 / Aceito: 25/03/2020.

\begin{abstract}
RESUMO
A partir da análise de informações divulgadas por órgãos do governo federal, em particular o Instituto Brasileiro de Geografia e Estatística (IBGE) e o Instituto Nacional de Previdência Social (INSS), entre outras fontes, o artigo procura demonstrar os impactos positivos gerados pelos investimentos sociais (especialmente a Previdência), feitos pelo Estado brasileiro, no Índice de Desenvolvimento Humano Municipal (IDHM) dos 32 municípios que integram a Associação dos Municípios do Alto Uruguai (AMAU), no norte do Rio Grande do Sul, entre 1988 e 2018. O levantamento realizado aponta que a Previdência - acompanhada por outros investimentos sociais em áreas como a Educação, a Saúde e a Assistência - gerou resultados significativos na melhora da qualidade de vida da população dessa região, especialmente às pessoas mais pobres e às residentes no meio rural, elevando os índices de desenvolvimento humano em todos esses municípios.
\end{abstract}

Palavras-chave: Município. AMAU. Previdência Social. Desenvolvimento Humano.

\begin{abstract}
Based on the analysis of information released by federal government agencies, in particular the Brazilian Institute of Geography and Statistics (IBGE) and the National Institute of Social Security (INSS), and other sources, this article seeks to demonstrate the positive impacts generated by social investments (especially Social Security), made by the Brazilian State, in the Municipal Human Development Index (MHDI) from the 32 municipalities that are part of the Association of Municipalities of Alto Uruguai (AMAU), in the north of Rio Grande do Sul, between 1988 and 2018. The survey carried out points that Social Security - followed by other social investments in areas such as Education, Health and Assistance - presented significant results in improving the quality of life of the population of this region, especially to the poorest ones and those living in rural areas, raising the human development indexes in all these municipalities.
\end{abstract}

Keywords: Municipality. AMAU. Social Security. Human Development.

\section{RESUMEN}

A partir del análisis de informaciones divulgadas por las agencias del gobierno federal, en particular el Instituto Brasileño de Geografía y Estadística (IBGE) y el Instituto Nacional de Seguridad Social (INSS), entre otras fuentes, el artículo busca demostrar los impactos positivos generados por las inversiones sociales. (especialmente Seguridad Social), elaborado por el Estado brasileño, en el Índice de Desarrollo Humano Municipal (IDHM) de los 32 municipios que conforman la Asociación de Municipios del Alto Uruguai (AMAU), en el norte de Rio Grande do Sul, entre 1988 y 2018. La encuesta realizada muestra que la Seguridad Social, acompañada de otras inversiones sociales en áreas como Educación, Salud y Asistencia, ha generado

\footnotetext{
${ }^{1}$ Doutorando em História na Universidade de Passo Fundo (UPF). E-mail: anacletoverpt@ yahoo.com.br

2 Doutor em Ciências Sociais pela Universidade Estadual de Campinas. Professor Adjunto no Curso de Licenciatura em Ciências Sociais e no Mestrado em História da Universidade Federal da Fronteira Sul (UFFS). E-mail: humberto.rocha@uffs.edu.br
} 
resultados significativos en la mejora de la calidad de vida de la población de esta región, especialmente de las personas más pobres y los residentes rurales, elevando las tasas de desarrollo humano en todos estos municipios. Palabras-chave: Municipio. AMAU. Seguridad Social. Desarrollo Humano.

\section{INTRODUÇÃO}

O presente artigo procura demonstrar os impactos positivos gerados pelos investimentos sociais (especialmente a Previdência), feitos pelo Estado brasileiro a partir da promulgação da Constituição Federal (1988), no Índice de Desenvolvimento Humano Municipal (IDHM) dos 32 municípios que integram a Associação dos Municípios do Alto Uruguai (AMAU), no norte do Rio Grande do Sul, entre 1988 e 2018. Para tal verificação, utilizam-se informações dos Censos do IBGE, do Fundo de Participação dos Municípios, das Leis Orçamentárias Anuais, da evolução do Índice de Desenvolvimento Humano Municipal e especialmente dos Benefícios da Previdência Social. Os municípios da AMAU compõem também o Conselho Regional de Desenvolvimento do Norte (Corede Norte ${ }^{3}$ ), como demonstra o Mapa 1, em sequência.

Ressalte-se que a grande presença da população rural tem sua origem e vínculo com o modelo de colonização adotado pelo governo do Rio Grande do Sul nessa região, ao fundar a Colônia Erechim , em 1908: garantir a ocupação desse território por meio de famílias de imigrantes europeus e seus descendentes e produzir alimentos para os centros urbanos emergentes no país. Saliente-se, outrossim, que esse território, especialmente em sua porção norte, é de relevo mais acentuado o que facilitou o desenvolvimento da agricultura de base familiar. Assim, os agricultores encontraram aí um "refúgio", não no sentido de estarem livres do domínio do capital, mas como um lugar "privilegiado" para a sua não exclusão (PIRAN, 2001, p. 39).

\footnotetext{
${ }^{3}$ Os Conselhos Regionais de Desenvolvimento - COREDEs -, criados oficialmente pela Lei estadual 10.283 de 17 de outubro de 1994, no Rio Grande do Sul, são fóruns de discussão para a promoção de políticas e ações que visam o desenvolvimento regional. O estado conta, atualmente, com 28 Conselhos Regionais de Desenvolvimento. Disponível em: <https://atlassocioeconomico.rs.gov.br/conselhos-regionais-dedesenvolvimento-coredes>. Acesso em: 04 jul. 2019.
} 


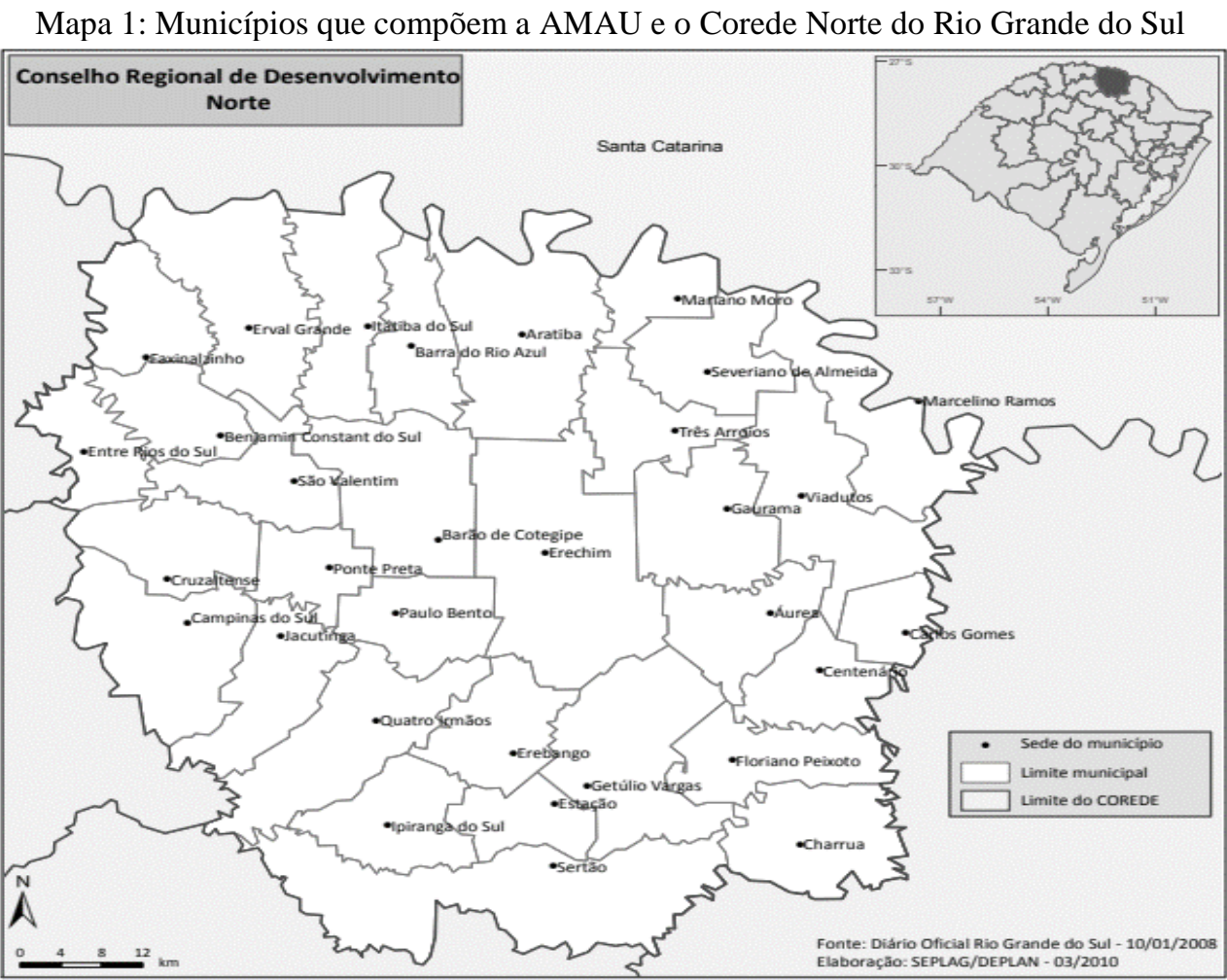

Fonte: Diário Oficial Rio Grande do Sul. Elaboração: Seplag/Deplan.

$\mathrm{O}$ artigo contém os seguintes tópicos: a agricultura de base familiar e os direitos sociais (pequeno histórico sobre o lento processo de conquista dos direitos sociais na região); a Previdência Social e o desenvolvimento regional (informações sobre os valores dos benefícios previdenciários e seu impacto nos municípios dessa região); a evolução do Índice de Desenvolvimento Humano Municipal (IDHM), entre 1991 e 2010, nessa região, em comparação com a do Rio Grande do Sul e do Brasil; os direitos sociais e o Estado em crise (breve contraponto em defesa dos direitos sociais frente à ideia hoje hegemônica no Brasil de que é preciso reduzir o papel do Estado na área social).

\section{A AGRICULTURA DE BASE FAMILIAR E OS DIREITOS SOCIAIS}

Desde a fundação da Colônia Erechim ${ }^{4}$, em 1908, o processo de ocupação do território que integra o Alto Uruguai rio-grandense, no norte do estado, no qual estão situados atualmente os 32 municípios da AMAU, caracterizou-se: pela forte presença dos imigrantes

\footnotetext{
${ }^{4}$ A Colônia Erechim foi criada em 1908, em ato do Presidente do Rio Grande do Sul, Carlos Barbosa, inserido na política de imigração e colonização que, no período, o governo estadual implementava. Tratou-se de uma colonização planejada pela Inspetoria de Terras, chefiada por Carlos Torres Gonçalves (CASSOL, 1979, p.28).
} 
europeus e de seus descendentes; pela pequena propriedade rural; pela prática da policultura (cultivo de vários produtos agrícolas); pela criação de animais (aves, suínos e bovinos) destinados ao consumo familiar e o excedente colocado à venda no mercado; pelo aproveitamento dos recursos naturais, como a fertilidade natural do solo; e pelo uso da mão de obra direta dos membros da família (BRUM, 1988, p. 27-30).

Entretanto, o processo de ocupação histórica desse território foi carregado de conflitos em defesa da terra entre os diversos sujeitos sociais (TEDESCO; VANIN, 2017). Nessa trajetória, os povos indígenas e caboclos foram as primeiras vítimas da exclusão, pois o governo estadual apostou no desenvolvimento da agricultura de base familiar através da população imigrante e dos seus descendentes.

No decorrer do tempo, o crescimento demográfico nessa região e o esgotamento da fertilidade natural dos solos provocou, especialmente a partir do fim da II Guerra Mundial, um processo de seleção/exclusão de agricultores que ainda não teve fim (PIRAN, 2001). Apesar disso, a agricultura de base familiar continua até hoje a ter papel destacado na economia regional. Dois fatos comprovam isso: de um lado, grande parcela dos setores urbanos industriais, comerciais e de serviços dessa região possuem relação direta com o campo, como é o caso das indústrias de suínos, aves, laticínios, indústrias de máquinas, cooperativas de produção e comercialização; e, de outro, a população rural nessa região é bem superior, em termos percentuais, comparativamente à população desse mesmo setor no Rio Grande do Sul e no Brasil, como pode ser visto na Tabela 1, em seguida.

Em 2010, como pode ser observado, a população rural da região da AMAU, percentualmente, era de 28,4\%, enquanto no Rio Grande do Sul era de 14,9\% e no Brasil, 15,64\%. A tabela acima revela também que dezessete municípios dessa região (mais de 50\%) possuíam maior população na área rural do que na urbana. Além disso, entre os 32 municípios, 21 possuíam menos de cinco mil habitantes e nove municípios, de cinco a 10 mil, ou seja, em termos populacionais, é uma região caracterizada por municípios com baixo número de habitantes. 
Tabela 1 - População dos municípios que compõem a AMAU

\begin{tabular}{|c|c|c|c|c|c|c|c|}
\hline Município & Total & Rural & Urbana & Município & Total & Rural & Urbana \\
\hline Aratiba & 6.565 & 3.249 & 3.316 & F. Peixoto & 2.018 & 1.726 & 292 \\
\hline Áurea & 3.665 & 2.128 & 1.537 & Gaurama & 5.862 & 2.474 & 3.388 \\
\hline B.Cotegipe & 6.529 & 2.563 & 3.966 & G. Vargas & 16.154 & 2.292 & 13.862 \\
\hline B. R. Azul & 2.003 & 1.600 & 403 & Ip. do Sul & 1.944 & 1.265 & 679 \\
\hline B. C. Sul & 2.307 & 1.966 & 341 & It. do Sul & 4.171 & 2.442 & 1.729 \\
\hline C. do Sul & 5.506 & 1.289 & 4.217 & Jacutinga & 3.633 & 1.060 & 2.573 \\
\hline C. Gomes & 1.607 & 1.229 & 378 & M. Ramos & 5.134 & 2.412 & 2.722 \\
\hline Centenário & 2.965 & 2.016 & 949 & M. Moro & 2.210 & 1.057 & 1.153 \\
\hline Charrua & 3.471 & 2.887 & 584 & P. Bento & 2.196 & 1.602 & 594 \\
\hline Cruzaltense & 2.141 & 1.652 & 489 & P. Preta & 1.750 & 1.238 & 512 \\
\hline E. R. Sul & 3.080 & 950 & 2.130 & Q. Irmãos & 1.775 & 859 & 916 \\
\hline Erebango & 2.970 & 1.012 & 1.958 & S.Valentim & 3.632 & 1.888 & 1.744 \\
\hline Erechim & 96.087 & 5.535 & 90.552 & Sertão & 6.294 & 2.907 & 3.387 \\
\hline E. Grande & 5.163 & 2.473 & 2.690 & S. Almeida & 3.842 & 2.443 & 1.399 \\
\hline Estação & 6.011 & 892 & 5.119 & T. Arroios & 2.855 & 1.828 & 1.027 \\
\hline Faxinalzinho & 2.567 & 1.294 & 1.273 & Viadutos & 5.311 & 2.668 & 2.643 \\
\hline AMAU & & & & & 221.418 & 62.896 & 158.522 \\
\hline$\%$ AMAU & & & & & $100 \%$ & $28,4 \%$ & $71,6 \%$ \\
\hline Total RS & & & & & 10.693 .929 & 1.593 .638 & 9.100 .291 \\
\hline$\% \mathrm{RS}$ & & & & & $100 \%$ & $14,9 \%$ & $85,1 \%$ \\
\hline Total Brasil & & & & & 190.755 .799 & 29.829 .995 & 160.925804 \\
\hline$\%$ Brasil & & & & & $100 \%$ & $15,64 \%$ & $84,36 \%$ \\
\hline
\end{tabular}

Fonte: IBGE, Censo Demográfico 2010. Tabela organizada pelos autores.

Historicamente, os direitos sociais demoraram a chegar ao interior do país. Apesar da economia regional ter como base a agricultura de base familiar, foram os direitos sociais e trabalhistas urbanos que nasceram primeiro na região, fruto da implementação, entre 1930 e 1945, da legislação sindical, trabalhista e previdenciária criada no país, durante o governo Vargas. Foi somente nas décadas de 1950 e 1960, através das Ligas Camponesas no Nordeste, que os trabalhadores rurais entraram na política nacional com voz própria (CARVALHO, 2016).

No Rio Grande do Sul, nesse período, constituíram-se dois movimentos: o Movimento dos Agricultores Sem Terra (Master), liderado por Leonel Brizola (PTB) e a Frente Agrária Gaúcha (FAG), liderada pela Igreja Católica. Na região da AMAU, apesar da força de Brizola e do PTB, foi a FAG quem organizou os sindicatos de trabalhadores rurais, a partir de 1962.

Com o golpe civil-militar de 1964, algumas organizações dos trabalhadores, como o Master e as Ligas Camponesas, foram duramente perseguidas no Brasil. Assim, os direitos previdenciários rurais começaram a sair do papel somente em 1971-1972, sob a outorga dos governos militares. Através da Lei Complementar $\mathrm{n}^{\circ} 11$, de 25.05.1971, é instituído o Programa de Assistência ao Trabalhador Rural (Prorural), regulamentado pelo Decreto 
69.919, de 11 de janeiro de 1972, que beneficiou também os trabalhadores rurais que viviam em regime de economia familiar, como era o caso da maioria dos agricultores dessa região.

No entanto, os benefícios eram restritos, pois apenas um membro da família tinha direito a acessar o Prorural, o "chefe da família”, geralmente o homem. Além disso, concediase somente aposentadoria por velhice aos 65 anos, invalidez, pensão por morte e auxíliofuneral. O valor também era menor que os benefícios urbanos. Assim, os agricultores eram beneficiados pelo valor de meio salário mínimo para aposentadorias e $30 \%$ para pensões. A Lei Complementar 16, de 30.10.1973, dispôs que a pensão, a partir de janeiro de 1974, passaria a ser de 50\% do valor do salário mínimo vigente no país (BERWANGER, 2011).

A partir do final dos anos 1970, aconteceu no Brasil ampla mobilização da sociedade brasileira que exigiu o fim do regime militar e a redemocratização do país. Esse processo culminou com a promulgação da nova Constituição Federal (1988) e a retomada das eleições diretas para presidente da República (1989).

Esse fenômeno de mobilização social também ocorreu na região da AMAU. Nesse lugar, o sindicalismo reorganizou-se e novos movimentos sociais rurais afirmaram-se. Entre as principais ações desenvolvidas por eles, nesse período, estava a participação ativa na organização de mobilizações estaduais e caravanas a Brasília (DF), em defesa dos direitos sociais (entre eles, a aposentadoria ao homem e à mulher rural) a fim de garanti-los na nova Constituição que estava sendo elaborada pelo Congresso Nacional.

Ressalte-se que a Constituição brasileira de 1988 foi reconhecida como "Constituição Cidadã", devido aos avanços sociais e democráticos obtidos, inéditos na história brasileira até então (CARVALHO, 2016). Entre as principais conquistas obtidas na Carta Magna, estavam os direitos sociais (em áreas como a Educação, a Saúde, a Assistência Social e a Previdência). A sua efetivação nos anos seguintes beneficiou a população brasileira, especialmente as famílias mais pobres e os trabalhadores e as trabalhadoras rurais de todo o país. Isso trouxe melhoria na renda e nas condições de vida de milhares de famílias na região da AMAU, como demonstrado a seguir.

\section{A PREVIDÊNCIA E O DESENVOLVIMENTO REGIONAL}

Historicamente, o pensamento teórico e político do Brasil esteve impregnado pela ideia de que é a modernização técnica e o crescimento econômico que explicam, justificam e motivam o desenvolvimento econômico brasileiro (DELGADO; THEODORO, 2009), ou 
seja, a igualdade como princípio basilar do desenvolvimento esteve sempre ausente, ou colocada em segundo plano.

Além disso, a efetivação da cidadania no Brasil e no mundo é tarefa sempre carregada de complexidade. Sua concepção, desenvolvida historicamente no mundo ocidental, inclui várias dimensões - traduzidas em direitos civis, políticos e sociais - difíceis de serem praticadas e, por isso, exigem a mobilização social permanente em sua defesa/implementação em cada país. Assim, uma cidadania plena, que garanta liberdade, participação e igualdade para todos, é quase inatingível, mas serve de parâmetro para julgar a qualidade de cidadania vivenciada em cada lugar e em cada momento histórico. (CARVALHO, 2016, p. 15).

Com base nisso, adota-se aqui uma visão de "desenvolvimento como liberdade" (SEN, 2010, p. 16-17), ou seja, o desenvolvimento é visto como expansão de liberdades substantivas para o ser humano, o que exige a remoção de todas as fontes de privação de liberdade, como a pobreza, a tirania, a carência de oportunidades econômicas, políticas, sociais, culturais e ambientais. Dessa forma, o desenvolvimento com equidade tem como ponto de partida a igualdade de oportunidades, de capacidades ou de resultados. Isso significa que os grupos sociais - historicamente excluídos às condições produtivas, aos benefícios do crescimento econômico e às garantias de um sistema de proteção social - devem ter acesso a tais direitos. Nesse sentido, a política social brasileira, em vigor a partir da Constituição Federal de 1988, especialmente o disposto no Título VIII, Da Ordem Social ${ }^{5}$, apesar de restrita, garantiu avanços importantes na efetivação da cidadania e para um desenvolvimento mais justo e humano.

E, pelas informações dispostas na sequência, afirmamos que foi isso que aconteceu na região da AMAU a partir de 1988, especialmente por causa dos investimentos que os governos das três esferas começaram a efetivar com reflexos diretos em cada município. A universalização da educação básica e da saúde (criação do Sistema Único de Saúde, SUS), os direitos da Previdência Social rural (beneficiando homens e mulheres) e os direitos da

\footnotetext{
5 A Constituição Federal do Brasil, no Título VIII, Da Ordem Social, determina, em seu artigo 193 que: “A ordem social tem como base o primado do trabalho, e como objetivo o bem-estar e a justiça sociais". E, no artigo 194, estabelece que: "A seguridade social compreende um conjunto integrado de ações de iniciativa dos Poderes Públicos e da sociedade, destinadas a assegurar os direitos relativos à saúde, à previdência e à assistência social". A partir disso, os artigos 196 ao 200 estabelecem as normas relativas ao direito à Saúde; os artigos 201 e 202 , as normas relativas à Previdência Social; os artigos 203 e 204, as normas relativas à Assistência Social. Além disso, os artigos 205 ao 214 estabelecem as normas relativas ao direito à Educação (Brasil, Constituição da República Federativa do Brasil de 1988).
} 
Assistência Social são recentes, mas representam conquistas imensas à população mais pobre e residente nos pequenos municípios.

Conforme Berwanger (2011, p. 174), as aposentadorias e pensões abrangem 71,2\% do total de rendimentos das famílias que vivem no campo no Nordeste e 41,5\% no Sul, o que ocasiona impactos econômicos e sociais positivos para a população rural. Em consequência, para os municípios com menores índices populacionais, os benefícios previdenciários injetam valores superiores ao que é repassado pela União através do Fundo de Participação dos Municípios (FPM). Isso também é constatado na região da AMAU, como pode ser observado na Tabela 2, a seguir. Nela, percebe-se que para $75 \%$ dos municípios dessa região, o valor injetado através dos Benefícios Previdenciários é superior ao volume de recursos recebido por meio do Fundo de Participação dos Municípios (FPM).

Por outro lado, a diferença é mais expressiva se forem somados todos os valores dos benefícios previdenciários em comparação com os valores do FPM, em nível da AMAU. Em 2017, a soma do valor do FPM nos municípios da AMAU corresponde a R\$ 227.925.031. Comparando com o valor recebido pelos benefícios previdenciários também desse ano, a diferença é gritante, pois alcança a cifra de $\mathrm{R} \$ 966.772 .563$. Portanto, em termos percentuais, o valor relativo ao FPM corresponde a $23,57 \%$ do que a população desses 32 municípios recebeu através dos benefícios previdenciários.

Registre-se, também, que pouco importa se as pessoas beneficiadas vão residir no perímetro urbano ou rural do município, pois como escreve Veiga (2003, p. 62), "as economias locais resultam de relações sinérgicas entre atividades urbanas e rurais". Ou seja, os recursos que as pessoas recebem dos benefícios previdenciários, em sua maior parte, são investidos no próprio município ou nas proximidades dentro da microrregião, fazendo girar os setores locais do comércio, da indústria, dos serviços e da agropecuária. 
Tabela 2 - Valor dos benefícios emitidos pela Previdência Social na AMAU e o repasse do Fundo de Participação dos Municípios (FPM), em 2017 (valores em R\$)

$\begin{array}{cccccccc}\text { Município } & \begin{array}{c}\text { Benef. } \\ \text { Emitidos }\end{array} & \text { FPM } & \begin{array}{c}\text { Benef. } \\ \text { /FPM }\end{array} & \text { Município } & \begin{array}{c}\text { Benef. } \\ \text { Emitidos }\end{array} & \text { FPM } & \begin{array}{c}\text { Benef. } \\ \text { /FPM }\end{array} \\ \text { Aratiba } & 36200391 & 6160136 & 5,88 & \text { F.Peixoto } & 5202025 & 6160136 & 0,84 \\ \text { Áurea } & 18818237 & 6160136 & 3,05 & \text { Gaurama } & 27924157 & 6160136 & 4,53 \\ \text { B. Coteg. } & 25760355 & 6160136 & 4,18 & \text { G. Vargas } & 89192557 & 10266893 & 8,69 \\ \text { B.R. Azul } & 6295456 & 6160136 & 1,02 & \text { Ip. do Sul } & 7664612 & 6160136 & 1,24 \\ \text { B.C.Sul } & 5694001 & 6160136 & 0,92 & \text { It. do Sul } & 15470202 & 6160136 & 2,51 \\ \text { C. do Sul } & 38457434 & 6160136 & 6,24 & \text { Jacutinga } & 19902470 & 6160136 & 3,23 \\ \text { C.Gomes } & 778448 & 6160136 & 0,13 & \text { M. Ramos } & 22873298 & 6160136 & 3,71 \\ \text { Centen. } & 11977587 & 6160136 & 1,94 & \text { M. Moro } & 8965887 & 6160136 & 1,46 \\ \text { Charrua } & 5997678 & 6160136 & 0,97 & \text { P.Bento } & 6031794 & 6160136 & 0,98 \\ \text { Cruzalt. } & 802850 & 6160136 & 0,13 & \text { P. Preta } & 3421128 & 6160136 & 0,56 \\ \text { E.R.Sul } & 12485485 & 6160136 & 2,03 & \text { Q. Irmãos } & 3258117 & 6160136 & 0,53 \\ \text { Erebango } & 7163786 & 6160136 & 1,16 & \text { S.Valentim } & 19952877 & 6160136 & 3,24 \\ \text { Erechim } & 446517922 & 32854058 & 13,59 & \text { Sertão } & 23747525 & 6160136 & 3,86 \\ \text { E.Grande } & 18396286 & 6160136 & 2,99 & \text { S. Almeida } & 17399566 & 6160136 & 2,82 \\ \text { Estação } & 13392797 & 6160136 & 2,17 & \text { T.Arroios } & 11360079 & 6160136 & 1,84 \\ \text { Faxinalz. } & 6609881 & 6160136 & 1,07 & \text { Viadutos } & 29057675 & 6160136 & 4,72 \\ & & & & & & & 7,63 \\ \text { AMAU } & 966772563 & 227925031 & 4,24 & \text { RS } & 40079289634 & 5252913184 & \\ \end{array}$

Fonte: ANFIP, 2019, p. 178-190. Tabela organizada pelos autores.

Outra informação importante que os dados da ANFIP (2019) indicam é o peso que os benefícios rurais tiveram na região da AMAU quando comparados com os do Rio Grande do Sul, em 2017. O valor estadual dos benefícios rurais foi de $\mathrm{R} \$ 7.336 .201 .544$, enquanto o valor total na AMAU foi de $\mathrm{R} \$ 362.036 .504$. No entanto, quando comparados com o valor total dos benefícios pagos (rurais e urbanos), há a seguinte constatação: os benefícios rurais no Rio Grande do Sul correspondem a 18,30\% do total dos benefícios, enquanto que na região da AMAU, equivalem a 37,44\% dos benefícios pagos nesse território. Ou seja, os benefícios rurais têm um peso muito maior nessa região.

Isso também é constatado na Tabela 3, a seguir, relativa aos valores dos benefícios, em 2018. Percebe-se que os valores dos benefícios rurais correspondem a 36,6\% do valor total (rurais e urbanos), uma pequena queda em comparação a 2017, mas ainda expressivo. Por outro lado, caso retirarmos os valores relativos a Erechim (o município-polo dessa região, que concentra a população urbana) e ficarmos com os valores dos demais 31 municípios, os benefícios urbanos somariam R 229.880 .902 e os benefícios rurais $\mathrm{R} \$$ 307.827.782. Os últimos correspondem, nesse caso, a 57,2\%. Isso indica a força da agricultura nessa região e o peso que os benefícios rurais têm nos municípios com baixo número de habitantes. 
Tabela 3 - Valores dos benefícios emitidos pelo Instituto Nacional de Previdência Social (INSS) que contemplaram a população dos municípios da AMAU (urbana e rural) em 2018

\begin{tabular}{cccccccc}
\hline Município & Benef. & Benef. & TOTAL & Município & Benef. & Benef. & TOTAL \\
& Urbanos & Rurais & & & Urbanos & Rurais & \\
Aratiba & 11988668 & 25592136 & 37580804 & F. Peixoto & 601131 & 4624086 & 5225217 \\
Áurea & 4565835 & 15280826 & 19846661 & Gaurama & 15259024 & 13375129 & 28634154 \\
B.Cotegipe & 11668818 & 14727151 & 26395969 & G. Vargas & 63318304 & 29313809 & 92632113 \\
B. R. Azul & 1157532 & 5294223 & 6451755 & Ip. do Sul & 2428761 & 5557384 & 7986144 \\
B. C. Sul & 1088873 & 4890103 & 5978976 & It. do Sul & 3339880 & 12017778 & 15357658 \\
C. do Sul & 15655893 & 24111415 & 39767309 & Jacutinga & 7982769 & 12485041 & 20467810 \\
C. Gomes & 242239 & 480997 & 723236 & M.Ramos & 11465390 & 12026072 & 23491462 \\
Centenário & 2360569 & 10147879 & 12508447 & M. Moro & 2979318 & 6270408 & 9249726 \\
Charrua & 929995 & 5212258 & 6142253 & P. Bento & 1848143 & 4475333 & 6323476 \\
Cruzaltense & 213309 & 1077477 & 1290786 & P. Preta & 795231 & 2701593 & 3496824 \\
E. Rios Sul & 6235284 & 7016902 & 13252186 & Q. Irmãos & 1254295 & 2122147 & 3376442 \\
Erebango & 4126017 & 3129360 & 7255377 & S.Valentim & 6037796 & 14130779 & 20168575 \\
Erechim & 404615552 & 58919032 & 463534584 & Sertão & 12061012 & 12920142 & 24981154 \\
E. Grande & 5914302 & 13040835 & 18955137 & S. Almeida & 6233287 & 11754136 & 17987423 \\
Estação & 12001142 & 2028631 & 14029773 & T. Arroios & 2961496 & 8745252 & 11706748 \\
Faxinalz. & 2074019 & 4847345 & 6921364 & Viadutos & 11092570 & 18431155 & 29523724 \\
TOTAL & & & & AMAU & 634496454 & 366746814 & 1001243267 \\
\hline
\end{tabular}

Fonte: Secretaria da Previdência, Ministério da Economia. Tabela organizada pelos autores.

A partir desses dados relativos aos municípios que integram a AMAU, é fácil concluir que a Previdência desempenha um papel preponderante, pois garante: a) de um lado, a melhoria da qualidade de vida das famílias rurais; b) e, de outro, o desenvolvimento econômico e social dos municípios com baixos índices populacionais.

$\mathrm{Na}$ tabela a seguir (Tabela 4), existe outra informação relevante: o valor total dos benefícios previdenciários supera a arrecadação municipal prevista para o ano de 2019 na Lei Orçamentária Anual (LOA) ${ }^{6}$, quando somados os valores dos 32 municípios. Constata-se que o total das receitas estimadas para 2019, quando somadas, corresponde a R\$968.462.232, ou seja, um percentual de $96,72 \%$ em relação ao que foi pago pelos benefícios previdenciários em 2018, R\$ 1.001.243.267 (Tabela 3). Verifica-se, dessa forma, que nessa região os benefícios previdenciários não apenas superam os valores recebidos pelos municípios via FPM, mas toda a arrecadação municipal anual prevista.

\footnotetext{
6 A Constituição Federal do Brasil, em seu artigo 165, prevê que o Poder Executivo (nas três esferas governamentais - federal, estadual e municipal) deverá encaminhar projetos de lei ao Poder Legislativo (para a análise e aprovação) para estabelecer: I - o plano plurianual (PPA); II - as diretrizes orçamentárias (LDO); III os orçamentos anuais (LOA). A lei que instituir o plano plurianual (PPA) será encaminhada a cada quatro anos e estabelecerá as diretrizes, objetivos e metas da administração pública para as despesas de capital e outras delas decorrentes e para as relativas aos programas de duração continuada. A lei de diretrizes orçamentárias (LDO) que será encaminhada anualmente compreenderá as metas e prioridades da administração pública, incluindo as despesas de capital para o exercício financeiro subsequente e orientará a elaboração da lei orçamentária anual. A lei orçamentária anual (LOA) compreenderá: o orçamento fiscal; o orçamento de investimento; e o orçamento da seguridade social (Constituição da República Federativa do Brasil de 1988).
} 


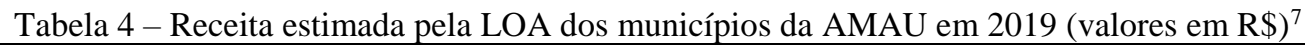

\begin{tabular}{cccc}
\hline Município & LOA 2019 & Município & LOA 2019 \\
Aratiba & 48.076 .428 & F. Peixoto & 17.298 .267 \\
Áurea & 18.817 .000 & Gaurama & 21.960 .000 \\
B. de Cotegipe & 24.700 .600 & G. Vargas & 55.537 .170 \\
B. do Rio Azul & 18.464 .849 & Ip. do Sul & 15.800 .000 \\
B. Constant do Sul & 15.331 .500 & Itatiba do Sul & 22.345 .000 \\
Campinas do Sul & 23.598 .410 & Jacutinga & 22.900 .000 \\
Carlos Gomes & 14.500 .000 & M. Ramos & 18.976 .000 \\
Centenário & 16.949 .550 & Mariano Moro & 14.170 .000 \\
Charrua & 14.000 .000 & Paulo Bento & 14.870 .259 \\
Cruzaltense & 13.500 .000 & Ponte Preta & 13.300 .000 \\
E. Rios do Sul & 23.500 .000 & Quatro Irmãos & 14.850 .000 \\
Erebango & 25.900 .000 & São Valentim & 20.000 .000 \\
Erechim & 305.000 .000 & Sertão & 27.248 .484 \\
Erval Grande & 23.000 .000 & S. de Almeida & 17.416 .987 \\
Estação & 28.300 .000 & Três Arroios & 21.427 .122 \\
Faxinalzinho & 15.600 .000 & Viadutos & 21.124 .606 \\
TOTAL & & AMAU & 968.462 .232 \\
\hline Fonte: Leis Orçamentárias Anuais dos 32 municípios da AMAU. Tabela organizada pelos autores.
\end{tabular}

Fonte: Leis Orçamentárias Anuais dos 32 municípios da AMAU. Tabela organizada pelos autores.

Em relação aos benefícios emitidos pelo INSS em favor da população residente na AMAU, além das informações contidas acima, destaca-se:

a) Os benefícios mensais emitidos em favor dos homens e das mulheres nos 32 municípios somam um número total de 70.064 (dados de outubro de 2018), o que significa que $31,26 \%$ da população regional é favorecida diretamente pelos direitos da Previdência Social, tendo em vista que a população estimada para 2018 nessa região era de 224.124 pessoas conforme o IBGE.

b) Os dados de outubro de $2018^{8}$ indicam também que a população beneficiada do sexo masculino (29.413 benefícios) corresponde a 41,98\% do total, enquanto a população beneficiada do sexo feminino (40.651 benefícios) corresponde a $58,02 \%$, demonstrando que as mulheres têm um peso maior que os homens nos valores financeiros injetados pela Previdência Social na economia do Alto Uruguai.

Por isso, tudo indica que os direitos sociais garantidos na Constituição de 1988, especialmente os previdenciários, tiveram impacto decisivo no desenvolvimento regional. Em favor desse argumento, a Confederação dos Trabalhadores na Agricultura (Contag) expressa

\footnotetext{
${ }^{7}$ As informações contidas nesta tabela foram buscadas nas páginas mantidas publicamente na internet pelos municípios citados e na página da Internet disponível em <https://leismunicipais.com.br/>. Acesso em 18 abr. 2019.

${ }^{8}$ As informações foram buscadas na página da Secretaria da Previdência, vinculada atualmente ao Ministério da Economia. Disponível em: <http://www.previdencia.gov.br/dados-abertos/estatisticas-municipais-2018/>. Acesso em: 18 abr. 2019.
} 
que a efetivação dos direitos ligados à previdência social foram fundamentais para a diminuição da pobreza e para uma melhor distribuição de renda, pois os benefícios rurais, espalhados em todo o território nacional, afetam a composição dos arranjos familiares, sua estrutura produtiva e a economia familiar rural, além de movimentar a economia, provocando um efeito multiplicador nos pequenos municípios de base agrícola (CONTAG, 2016).

A partir do conjunto das afirmações acima, acreditamos que os benefícios previdenciários efetivados a partir de 1988 não só beneficiaram milhares de pessoas residentes nos 32 municípios da AMAU, mas impulsionaram o desenvolvimento regional, tanto do ponto de vista econômico (renda e movimentação da economia regional) como na geração de maior qualidade de vida à população. Isso pode ser constatado também na evolução do IDHM, assunto tratado na sequência.

\section{A EVOLUÇÃO DO IDHM NA REGIÃO DA AMAU (1991-2010)}

A fim de confirmar ou não o impacto na qualidade de vida da população dessa região, a partir da implementação dos direitos sociais aprovados na Constituição Federal de 1988, é importante verificar como foi a evolução do Índice de Desenvolvimento Humano Municipal $(\text { IDHM })^{9}$, entre 1991 e 2010 nos 32 municípios da AMAU em comparação com a do Rio Grande do Sul e do Brasil. Analisemos primeiro o IDHM 1991.

A Tabela 6, a seguir, indica que, em 1991, o IDHM do Rio Grande do Sul $(0,542)$ era maior que o IDHM dos municípios da AMAU, com exceção de Erechim $(0,578)$. Já em relação ao Brasil, o seu IDHM (0,493) superava a maioria dos municípios da AMAU, com exceção de Campinas do Sul (0,528), Erechim (0,578), Estação (0,534), Gaurama (0,498), Getúlio Vargas (0,532), Jacutinga $(0,508)$ e Sertão $(0,495)$.

\footnotetext{
${ }^{9}$ O IDHM é uma medida composta de indicadores de três dimensões do desenvolvimento humano: longevidade, educação e renda, seguindo as mesmas três dimensões do Índice de Desenvolvimento Humano (IDH), adotado pelo Programa das Nações Unidas para o Desenvolvimento (PNUD), mas vai além: adequa a metodologia global ao contexto brasileiro e à disponibilidade de indicadores do (IDH) nacionais. O IDHM é um número que varia entre 0 e 1 . Quanto mais próximo de 1, maior o desenvolvimento humano de uma unidade federativa ou município. As faixas são as seguintes: muito baixo = até 0,499 ; baixo =0,500 a 0,599; médio =0,600 a 0,699; alto $=0,700$ a 0,$799 ;$ muito alto $=$ acima de 0,800 . Disponível em: <http://www.atlasbrasil.org.br/2013/pt/o_atlas/idhm/>. Acesso em: 10 jul. 2019.
} 
Tabela 6 - IDHM nos municípios da AMAU em 1991

\begin{tabular}{cccccccccccc}
\hline Munic. & IDHM & Renda & Educ. & Long. & EVida & Munic. & IDHM & Renda & Educ. & Long. & EVida \\
Aratiba & 0,455 & 0,575 & 0,218 & 0,750 & 70,01 & F. Peix. & 0,347 & 0,536 & 0,108 & 0,719 & 68,13 \\
Áurea & 0,408 & 0,535 & 0,180 & 0,705 & 67,32 & Gaurama & 0,498 & 0,579 & 0,273 & 0,781 & 71,86 \\
B.Coteg. & 0,450 & 0,561 & 0,229 & 0,710 & 67,61 & G.Vargas & 0,532 & 0,612 & 0,347 & 0,710 & 67,62 \\
B.RAzul & 0,443 & 0,556 & 0,214 & 0,733 & 68,95 & Ipir. Sul & 0,488 & 0,606 & 0,244 & 0,788 & 72,29 \\
B.C. Sul & 0,312 & 0,423 & 0,110 & 0,653 & 64,18 & Itat. Sul & 0,374 & 0,467 & 0,159 & 0,705 & 67,32 \\
C. Sul & 0,528 & 0,632 & 0,320 & 0,727 & 68,61 & Jacutinga & 0,508 & 0,597 & 0,299 & 0,734 & 69,06 \\
C. Gom. & 0,423 & 0,600 & 0,169 & 0,746 & 69,73 & M.Ram. & 0,478 & 0,597 & 0,241 & 0,759 & 70,53 \\
Centen. & 0,390 & 0,572 & 0,138 & 0,754 & 70,23 & M.Moro & 0,483 & 0,621 & 0,238 & 0,763 & 70,79 \\
Charrua & 0,375 & 0,532 & 0,130 & 0,765 & 70,92 & P.Bento & 0,407 & 0,498 & 0,178 & 0,763 & 70,79 \\
Cruzalt. & 0,356 & 0,489 & 0,130 & 0,710 & 67,61 & P.Preta & 0,336 & 0,477 & 0,106 & 0,750 & 69,97 \\
E. R. Sul & 0,382 & 0,548 & 0,143 & 0,710 & 67,61 & Q.Irmãos & 0,330 & 0,485 & 0,105 & 0,705 & 67,32 \\
Ereban. & 0,459 & 0,557 & 0,235 & 0,737 & 69,21 & S Valent. & 0,458 & 0,601 & 0,219 & 0,729 & 68,75 \\
Erechim & 0,578 & 0,686 & 0,378 & 0,746 & 69,73 & Sertão & 0,495 & 0,552 & 0,293 & 0,752 & 70,12 \\
E.Grand. & 0,338 & 0,531 & 0,095 & 0,765 & 70,90 & S. Alm. & 0,451 & 0,533 & 0,230 & 0,750 & 69,97 \\
Estação & 0,534 & 0,600 & 0,340 & 0,748 & 69,86 & T.Arro. & 0,482 & 0,612 & 0,240 & 0,763 & 70,79 \\
Faxinalz & 0,408 & 0,514 & 0,201 & 0,659 & 64,53 & Viadutos & 0,417 & 0,595 & 0,163 & 0,745 & 69,69 \\
RS & 0,542 & 0,667 & 0,328 & 0,729 & 68,76 & BRASIL & 0,493 & 0,647 & 0,279 & 0,662 & 64,73 \\
\hline
\end{tabular}

Fonte: Atlas Brasil 2013. Tabela elaborada pelos autores.

Comparativamente com o Brasil e o Rio Grande do Sul, constata-se que o principal problema regional nessa época estava localizado na questão Renda. Apenas o município de Erechim $(0,686)$ apresentou índice superior que a média estadual $(0,667)$ e nacional $(0,647)$. No quesito Renda, por faixa de IDHM , os municípios da região estavam assim: seis estavam com Muito Baixo IDHM, 17 com índice Baixo e nove situados no Médio IDHM. Entretanto, se forem levados em consideração a evolução do IDHM por faixa, percebe-se que o grande problema regional estava localizado na área educacional, pois todos os municípios da AMAU localizavam-se na faixa Muito Baixo. Em comparação com o estado e o país, apenas Erechim $(0,378)$, Estação $(0,340)$ e Getúlio Vargas $(0,347)$, possuíam índices superiores à média estadual $(0,328)$ e nacional $(0,279)$. Campinas do Sul $(0,320)$, Jacutinga $(0,299)$ e Sertão $(0,293)$ possuíam índices superiores à média nacional, mas abaixo da estadual.

Por outro lado, na dimensão Longevidade, os municípios da AMAU estavam melhor situados. Apenas os municípios de Benjamin Constant do Sul $(0,653)$ e Faxinalzinho $(0,659)$ possuíam índices inferiores à média nacional $(0,662)$ e estadual $(0,729)$. Apesar disso, esses dois municípios estavam situados na faixa de Médio IDHM. Em relação ao Rio Grande do Sul $(0,729)$, vários municípios possuíam índices abaixo, mas superiores à média federal $(0,662)$ : Áurea (0,705), Campinas do Sul $(0,727)$, Barão de Cotegipe $(0,710)$, Cruzaltense (0,710), Entre Rios do Sul (0,710), Floriano Peixoto (0,719), Getúlio Vargas (0,710), Itatiba do Sul $(0,705)$, Quatro Irmãos $(0,705)$ e São Valentim $(0,729)$, que teve um índice igual à média estadual. Apesar disso, o IDHM Longevidade desses municípios estava bem próximo da média estadual e, se forem levados em conta o IDHM por faixa, todos estavam situados na 
faixa de Alto IDHM. Além disso, chama a atenção que 13 municípios dessa região, nesse índice específico, estavam situados, em 1991, na faixa de Muito Alto IDHM.

Analisamos, agora, o IDHM do ano 2000 (Tabela 7). Percebe-se que no ano 2000, os municípios da AMAU obtiveram índices melhores que os de 1991. O IDHM do Rio Grande do Sul $(0,664)$ e o IDHM do Brasil $(0,612)$ eram superados pelos seguintes municípios: Campinas do Sul (0,665), Erechim (0,696), Getúlio Vargas (0,665), Ipiranga do Sul $(0,673)$ e Sertão $(0,684)$. Além disso, os seguintes municípios possuíam índices superiores ao nacional, mas abaixo do estadual: Aratiba (0,615), Barão de Cotegipe $(0,633)$, Estação $(0,662)$, Gaurama (0,662), Jacutinga (0,620), Marcelino Ramos (0,631), Mariano Moro $(0,656)$, Severiano de Almeida $(0,633)$ e Três Arroios $(0,637)$.

Em relação à Renda, o IDHM do Brasil $(0,692)$ era na região somente superado pelos municípios de Erechim (0,720) e Mariano Moro (0,706). E nenhum município superou o IDHM do Rio Grande do Sul (0,720), apesar de que Erechim tenha obtido o mesmo índice. Ou seja, em comparação com o estado e o país, os municípios da região continuavam a ter na questão Renda, o seu problema central. Já na comparação com o ano de 1991, os municípios melhoraram seus índices: oito municípios estavam na faixa Baixo IDHM, 22 com Médio IDHM e dois com Alto IDHM.

Tabela 7 - IDHM nos municípios da AMAU em 2000

\begin{tabular}{cccccccccccc}
\hline Munic. & IDHM & Renda & Educ. & Long. & Evida & Munic. & IDHM & Renda & Educ. & Long. & EVida \\
Aratiba & 0,615 & 0,633 & 0,457 & 0,804 & 73,26 & F. Peix. & 0,532 & 0,579 & 0,328 & 0,792 & 72,52 \\
Áurea & 0,582 & 0,596 & 0,431 & 0,766 & 70,96 & Gaurama & 0,662 & 0,675 & 0,511 & 0,841 & 75,46 \\
B.Coteg. & 0,633 & 0,666 & 0,511 & 0,746 & 69,74 & G.Vargas & 0,665 & 0,671 & 0,547 & 0,800 & 73,02 \\
B.R.Azul & 0,561 & 0,649 & 0,355 & 0,766 & 70,94 & Ipir.Sul & 0,673 & 0,687 & 0,514 & 0,862 & 76,72 \\
B. C. Sul & 0,450 & 0,535 & 0,229 & 0,743 & 69,60 & Itat.Sul & 0,533 & 0,595 & 0,328 & 0,775 & 71,51 \\
C. do Sul & 0,665 & 0,678 & 0,545 & 0,796 & 72,78 & Jacutinga & 0,620 & 0,645 & 0,474 & 0,781 & 71,87 \\
C.Gomes & 0,596 & 0,662 & 0,404 & 0,793 & 72,55 & MRamos & 0,631 & 0,657 & 0,478 & 0,799 & 72,94 \\
Centen. & 0,545 & 0,555 & 0,367 & 0,793 & 72,56 & M.Moro & 0,656 & 0,706 & 0,497 & 0,806 & 73,38 \\
Charrua & 0,501 & 0,588 & 0,249 & 0,858 & 76,50 & P.Bento & 0,608 & 0,616 & 0,451 & 0,811 & 73,65 \\
Cruzalt. & 0,582 & 0,626 & 0,397 & 0,792 & 72,52 & P.Preta & 0,560 & 0,582 & 0,380 & 0,794 & 72,61 \\
E. R. Sul & 0,595 & 0,663 & 0,415 & 0,766 & 70,94 & Q.Irmãos & 0,504 & 0,539 & 0,307 & 0,775 & 71,51 \\
Ereb. & 0,606 & 0,606 & 0,465 & 0,790 & 72,42 & S.Valent. & 0,544 & 0,608 & 0,342 & 0,775 & 71,51 \\
Erechim & 0,696 & 0,720 & 0,570 & 0,820 & 74,18 & Sertão & 0,684 & 0,676 & 0,571 & 0,830 & 74,82 \\
E.Grande & 0,560 & 0,612 & 0,335 & 0,858 & 76,50 & S.Alm. & 0,633 & 0,657 & 0,475 & 0,811 & 73,65 \\
Estação & 0,662 & 0,663 & 0,558 & 0,784 & 72,05 & T.Arro. & 0,637 & 0,649 & 0,473 & 0,843 & 75,57 \\
Faxinalz. & 0,574 & 0,629 & 0,394 & 0,762 & 70,69 & Viadutos & 0,567 & 0,658 & 0,355 & 0,780 & 71,77 \\
RS & 0,664 & 0,720 & 0,505 & 0,804 & 73,22 & BRASIL & 0,612 & 0,692 & 0,456 & 0,727 & 68,61 \\
\hline & \multicolumn{8}{c}{ Fonte: Atlas Brasil 2013. Tabela elaborada pelos autores. } & &
\end{tabular}

Em relação à Educação, o IDHM do Brasil $(0,456)$ e do Rio Grande do Sul $(0,505)$ foi superado pelos seguintes municípios: Barão de Cotegipe (0,511), Campinas do Sul $(0,545)$, Erechim (0,570), Estação (0,558), Gaurama (0, 511), Getúlio Vargas (0,547), Ipiranga do Sul $(0,514)$ e Sertão $(0,571)$. Além disso, alguns municípios superaram o IDHM do Brasil e não 
o do Rio Grande do Sul: Aratiba (0,457), Erebango (0,465), Jacutinga (0,474), Marcelino Ramos $(0,478)$, Mariano Moro $(0,497)$, Severiano de Almeida $(0,475)$ e Três Arroios $(0,473)$. Em relação à faixa, apesar da melhora dos índices em comparação com o ano de 1991, o IDHM Educação era o principal problema regional: 24 municípios continuavam com Muito Baixo IDHM e oito estavam com Baixo IDHM.

Em relação à Longevidade, o IDHM do Brasil $(0,727)$ foi superado por todos os municípios da AMAU. Já em relação ao Rio Grande do Sul $(0,804)$, há empate com o município de Aratiba $(0,804)$. E muitos municípios dessa região estavam abaixo da média estadual. Em relação à faixa do IDHM (Longevidade), os municípios estavam assim: 20 estavam com Alto IDHM e 12 com Muito Alto IDHM.

Analisemos agora o resultado do IDHM desses municípios em relação ao ano 2010 (Tabela 8).

Tabela 8 - IDHM nos municípios da AMAU em 2010

\begin{tabular}{cccccccccccc}
\hline Munic. & IDHM & Renda & Educ. & Long. & EVida & Munic. & IDHM & Renda & Educ. & Long. & EVida \\
Aratiba & 0,772 & 0,801 & 0,670 & 0,856 & 76,38 & F. Peix. & 0,663 & 0,701 & 0,486 & 0,854 & 76,23 \\
Áurea & 0,707 & 0,715 & 0,588 & 0,841 & 75,48 & Gaurama & 0,738 & 0,733 & 0,643 & 0,852 & 76,09 \\
B Coteg. & 0,719 & 0,745 & 0,593 & 0,842 & 75,49 & GVargas & 0,746 & 0,747 & 0,658 & 0,843 & 75,55 \\
B.RAzul & 0,723 & 0,703 & 0,638 & 0,842 & 75,50 & Ipir. Sul & 0,791 & 0,818 & 0,698 & 0,866 & 76,94 \\
B.C. Sul & 0,619 & 0,601 & 0,492 & 0,801 & 73,03 & Itat. Sul & 0,681 & 0,696 & 0,567 & 0,801 & 73,03 \\
C. Sul & 0,760 & 0,753 & 0,691 & 0,842 & 75,49 & Jacutinga & 0,726 & 0,703 & 0,636 & 0,855 & 76,30 \\
CGomes & 0,739 & 0,732 & 0,622 & 0,886 & 78,14 & MRamos & 0,724 & 0,735 & 0,618 & 0,834 & 75,03 \\
Centen. & 0,701 & 0,707 & 0,569 & 0,856 & 76,36 & M.Moro & 0,730 & 0,763 & 0,604 & 0,843 & 75,55 \\
Charrua & 0,620 & 0,699 & 0,385 & 0,885 & 78,12 & P.Bento & 0,710 & 0,730 & 0,571 & 0,858 & 76,49 \\
Cruzalt. & 0,719 & 0,724 & 0,605 & 0,849 & 75,92 & P.Preta & 0,725 & 0,727 & 0,600 & 0,874 & 77,44 \\
E. R.Sul & 0,703 & 0,709 & 0,572 & 0,857 & 76,40 & Q.Irmãos & 0,689 & 0,695 & 0,565 & 0,833 & 74,98 \\
Ereb. & 0,712 & 0,689 & 0,626 & 0,837 & 75,24 & SValent. & 0,720 & 0,745 & 0,612 & 0,820 & 74,18 \\
Erechim & 0,776 & 0,782 & 0,716 & 0,833 & 74,95 & Sertão & 0,751 & 0,746 & 0,678 & 0,837 & 75,23 \\
EGrande & 0,681 & 0,713 & 0,501 & 0,885 & 78,12 & S. Alm. & 0,752 & 0,738 & 0,670 & 0,861 & 76,66 \\
Estação & 0,753 & 0,752 & 0,674 & 0,843 & 75,55 & T. Arro. & 0,791 & 0,843 & 0,689 & 0,851 & 76,08 \\
Faxinalz & 0,666 & 0,646 & 0,571 & 0,801 & 73,03 & Viadutos & 0,702 & 0,715 & 0,561 & 0,864 & 76,81 \\
RS & 0,746 & 0,769 & 0,642 & 0,840 & 75,38 & BRASIL & 0,727 & 0,739 & 0,637 & 0,816 & 73,94 \\
\hline
\end{tabular}

Fonte: Atlas Brasil 2013. Tabela elaborada pelos autores.

Percebe-se que, em 2010, o IDHM do Brasil $(0,727)$ e o IDHM do Rio Grande do Sul $(0,746)$, foi superado pelos seguintes municípios da AMAU: Aratiba (0,772), Campinas do Sul (0,760), Erechim (0,776), Estação (0,753), Ipiranga do Sul (0,791), Sertão (0,751), Severiano de Almeida $(0,752)$ e Três Arroios (0,791). Além disso, o IDHM de Getúlio Vargas $(0,746)$ ficou igual com o do Rio Grande do Sul e superou o do Brasil. E também os municípios de Carlos Gomes (0,739), Gaurama (0,738) e Mariano Moro $(0,730)$ ficaram abaixo da média estadual, mas acima da média nacional.

Em relação à Renda, em 2010, os municípios da AMAU melhoraram muito em relação aos índices apurados em 1991 e 2000, mas continuava a ser um problema central. O IDHM 
do Brasil $(0,739)$ foi superado por: Aratiba $(0,801)$, Barão de Cotegipe $(0,745)$, Campinas do Sul (0,753), Erechim (0,782), Estação (0,752), Getúlio Vargas (0,747), Ipiranga do Sul $(0,818)$, Mariano Moro (0,763), São Valentim $(0,745)$, Sertão $(0,746)$ e Três Arroios $(0,843)$. Já o IDHM do Rio Grande do Sul $(0,769)$ foi superado apenas por Aratiba $(0,801)$, Erechim $(0,782)$ e Ipiranga do Sul $(0,818)$. Já por faixa de IDHM, os municípios também melhoraram em 2010: seis estavam com Médio IDHM, 23 com Alto IDHM e três com Muito Alto IDHM.

Em relação à Educação, em 2010, os municípios da AMAU também melhoraram comparativamente a 1991. O IDHM do Brasil $(0,637)$ e o do Rio Grande do Sul $(0,642)$ foram superados pelos municípios: Aratiba (0,670), Campinas do Sul (0,691), Erechim $(0,716)$, Estação $(0,674)$, Gaurama (0,643), Getúlio Vargas (0,658), Ipiranga do Sul $(0,698)$, Sertão $(0,678)$, Severiano de Almeida $(0,670)$ e Três Arroios $(0,689)$. Além disso, o município de Barra do Rio Azul $(0,638)$ superou o índice do Brasil. Em relação à faixa de IDHM, a situação em 2010 era: três municípios continuavam com índice Muito Baixo IDHM, 10 com Baixo IDHM, 18 com Médio IDHM e um estava com Alto IDHM. Em comparação com 2000, os índices melhoraram, apesar de continuarem baixos.

Em relação à Longevidade, em 2010, os municípios da AMAU continuaram a ter bons índices. Em relação ao IDHM nacional $(0,816)$ e estadual $(0,840)$, apenas os municípios: Benjamin Constant do Sul $(0,801)$, Faxinalzinho $(0,801)$ e Itatiba do Sul $(0,801)$ tinham índices abaixo. E os municípios de Erebango (0,837), Erechim $(0,833)$, Marcelino Ramos $(0,834)$, Quatro Irmãos $(0,833)$, São Valentim $(0,820)$ e Sertão $(0,837)$ possuíam índices abaixo da média estadual, mas superiores à média nacional. No entanto, saliente-se que todos os 32 municípios estavam situados na faixa Muito Alto IDHM.

E, para concluir esse tópico, analisemos a evolução do IDHM por faixa, 1991-2010 (Tabela 9). 
Tabela 9 - Evolução do IDHM por faixa nos municípios da AMAU, entre 1991 e 2010

\begin{tabular}{|c|c|c|c|c|c|c|c|}
\hline Município & 1991 & 2000 & 2010 & Município & 1991 & 2000 & 2010 \\
\hline Aratiba & MBaixo & Médio & Muito alto & F.Peixoto & MBaixo & Baixo & Médio \\
\hline Áurea & MBaixo & Baixo & Alto & Gaurama & MBaixo & Médio & Alto \\
\hline B.Cotegipe & MBaixo & Médio & Alto & G. Vargas & Baixo & Médio & Alto \\
\hline B.Rio Azul & MBaixo & Baixo & Alto & Ip. do Sul & MBaixo & Médio & Muito alto \\
\hline B.Const.Sul & MBaixo & Mbaixo & Médio & It. do Sul & MBaixo & Baixo & Médio \\
\hline Camp. Sul & Baixo & Médio & Alto & Jacutinga & Baixo & Médio & Alto \\
\hline C. Gomes & MBaixo & Baixo & Alto & M. Ramos & MBaixo & Médio & Alto \\
\hline Centenário & MBaixo & Baixo & Alto & M. Moro & MBaixo & Médio & Alto \\
\hline Charrua & MBaixo & Baixo & Médio & P. Bento & MBaixo & Médio & Alto \\
\hline Cruzaltense & MBaixo & Baixo & Alto & P. Preta & MBaixo & Baixo & Alto \\
\hline E. Rios Sul & MBaixo & Baixo & Alto & Q. Irmãos & MBaixo & Baixo & Médio \\
\hline Erebango & MBaixo & Médio & Alto & S.Valentim & MBaixo & Baixo & Alto \\
\hline Erechim & Baixo & Médio & Alto & Sertão & MBaixo & Médio & Alto \\
\hline E. Grande & MBaixo & Baixo & Médio & S.Almeida & MBaixo & Médio & Alto \\
\hline Estação & Baixo & Médio & Alto & T. Arroios & MBaixo & Médio & Muito alto \\
\hline Faxinalzinho & MBaixo & Baixo & Médio & Viadutos & MBaixo & Baixo & Alto \\
\hline $\mathrm{RS}$ & Baixo & Médio & Alto & Brasil & MBaixo & Médio & Alto \\
\hline
\end{tabular}

Fonte: Atlas Brasil 2013. Tabela elaborada pelo autores.

Acreditamos que essa tabela é muito elucidativa. Somadas as três dimensões do desenvolvimento humano consideradas (Renda, Educação e Longevidade), em 1991, os municípios da AMAU estavam situados na faixa Muito Baixo IDHM (27 municípios) e Baixo IDHM (cinco municípios). Em 2000, existia apenas um município na faixa Muito Baixo IDHM; 15 municípios na faixa Baixo IDHM e 16 já estavam na faixa Médio IDHM. E, em 2010, todos os municípios já estavam situados nas faixas Médio IDHM (sete municípios), Alto IDHM (22 municípios) e Muito Alto IDHM (três municípios).

Quando consideradas individualmente essas dimensões, temos o seguinte resultado nessa região: 1) na dimensão Renda, em 1991, seis municípios estavam com Muito Baixo IDHM, 17 com Baixo e 9 na faixa Médio IDHM; em 2010, todos melhoraram: seis com Médio, 23 com Alto e três Muito Alto IDHM; 2) na dimensão Educação, em 1991, os 32 municípios estavam situados na faixa Muito Baixo IDHM; em 2010, três ainda continuavam na faixa Muito Baixo, mas 10 evoluíram para Baixo, 18 para Médio e um para Alto IDHM; 3) na dimensão Longevidade, em 1991, dois municípios estavam com Médio IDHM, 17 com Alto e 13 Muito Alto; em 2010, os 32 municípios estavam localizados na faixa Muito Alto IDHM.

Dessa forma, concluímos que, entre 1991 e 2010, a aplicação de investimentos públicos municipais, estaduais e federais na área social (especialmente na Previdência, na Educação, na Saúde e na Assistência) garantiram impacto significativo na qualidade de vida da população residente nessa região, essencialmente para as pessoas mais pobres e para aquelas residentes no meio rural. A evolução do IDHM nas suas três dimensões comprova isso. Além disso, o desenvolvimento humano regional conseguiu acompanhar a evolução 
ocorrida em nível estadual e nacional. Em vários municípios, constata-se, inclusive, a sua superação.

No último tópico, em breves palavras, a partir da análise regional feita até aqui, apresentamos alguns argumentos em contraponto à ideia hegemônica atual de que é preciso reduzir os investimentos públicos do Estado na área social.

\section{OS DIREITOS SOCIAIS E O ESTADO EM CRISE}

A história brasileira, desde o período colonial, caracteriza-se por grandes contrastes sociais. Assim, o Brasil carrega a marca de ser um dos países mais desiguais do mundo: há enorme concentração de renda nas mãos de poucas pessoas e níveis altíssimos de pobreza para grande parcela da população (CARVALHO, 2016, p. 210).

No entanto, na história recente do Brasil, a partir do processo de redemocratização que culminou com a promulgação da nova Constituição (1988), vivenciou-se um período singular de conquistas políticas, sociais e econômicas que beneficiaram a maioria da população brasileira. A cidadania foi ampliada nas diversas partes do país, alcançando também as populações mais pobres e as que vivem no meio rural.

Nesse sentido, em 2011, um comunicado do Instituto de Pesquisa Econômica Aplicada (IPEA) registrava que a política social brasileira estruturava as condições básicas de vida da população, sobretudo aquelas que diziam respeito à pobreza e à desigualdade. Reconhecia, então, que os benefícios sociais haviam se transformado em "poderoso instrumento" para a transferência de renda aos mais necessitados e, além disso, contribuíam decisivamente para criar amplo mercado interno de consumo de massa. Dessa forma, inclusive, o país tinha construído uma melhor capacidade para enfrentar a crise financeira mundial ocorrida em 2008 (Comunicado do IPEA nº 75, 2011).

Entretanto, de 2013 até o presente, tudo isso foi posto à prova. Avritzer (2019, p. 141) caracteriza esse período como de "regressão democrática", pois colocou em dúvida pontos centrais da democracia e os direitos sociais. Nesse período, sucederam-se vários fatos que contribuíram para isso (mobilizações de setores da sociedade com pautas conservadoras exigindo redução do papel do Estado, denúncias fortes de corrupção atingindo lideranças governamentais e dos principais partidos políticos, estagnação econômica, recessão, desemprego, entre outros). Essa soma de fatores provocou uma crise política e econômica ao mesmo tempo, culminando com o impeachment da presidente Dilma Rousseff, em 2016. 
Além disso, abriu caminho para que os novos governantes - Michel Temer (2016-2018) e Jair Bolsonaro (a partir de 2019) -, com o apoio dos setores econômicos nacionais e internacionais, implantassem uma agenda política, social e econômica conservadora, que tem como principais motes o ajuste fiscal e a redução do papel do Estado. Essa agenda provoca impactos negativos nessa experiência recente de ampliação de direitos e da cidadania.

Cabe destacar que essa crise que vive o Estado (e a política) não é apenas brasileira. Observa-se que o Estado passa por uma profunda crise de identidade no mundo inteiro (Estados Unidos, Inglaterra, França, Grécia, Espanha, Argentina, Chile, Venezuela, Brasil, Coréia do Sul, Egito, entre outros países). Além disso, em países considerados potências mundiais como China e Rússia, consolidaram-se regimes autoritários de governo. Essa crise revela-se por sintomas como: ruptura da relação entre governantes e governados; deslegitimação da representação política; desconfiança nas instituições; colapso gradual da democracia liberal (um modelo político de representação e governança que havia se consolidado nas últimas décadas contra os estados autoritários). Ocorre, portanto, um divórcio entre poder e política. Além disso, o processo de globalização da economia desestruturou as economias nacionais e limitou a capacidade do Estado-nação de resolver os problemas em qualquer dimensão (econômica, social ou ambiental). O Estado, portanto, foi expropriado de uma parcela grande de seu poder de levar as coisas a cabo: não dispõe mais de recursos e meios para controlar os mercados cada vez mais globais (BAUMAN, 2016, p. 21-22; CASTELLS, 2018, p. 7-8).

Voltando ao Brasil, o relatório "País Estagnado: um retrato das desigualdades brasileiras 2018”, da Oxfam Brasil não deixa dúvidas sobre o contexto negativo vivenciado atualmente. $\mathrm{O}$ texto de aproximadamente 70 páginas começa assim:

Completamos 30 anos de nossa Constituição Federal, principal instrumento para a redução de desigualdades na história do Brasil. Infelizmente, este marco não enseja comemorações no presente contexto. Pelo contrário, vemos conquistas importantes serem desmanteladas e o prenúncio de um período de crescimento da pobreza e das desigualdades no país (Oxfam Brasil, 2018, p. $6)$.

Nesse cenário, foram implementadas medidas como a da Reforma Trabalhista (Lei 13.467, de 2017, aprovada para flexibilizar o mercado de trabalho, simplificar as relações entre trabalhadores e empregadores, com a promessa de elevar a empregabilidade no país), do Teto de Gastos (Emenda Constitucional no 95, que entrou em vigor em dezembro de 2016 e instituiu um novo regime fiscal, através do congelamento dos gastos federais por 20 anos, 
atingindo também os investimentos na Educação e na Saúde), e a Reforma da Previdência, em 2019. Assim, ganharam força os argumentos daqueles que defendem a redução do papel do Estado na área social.

Esse modelo e esse caminho são os mais corretos? Tudo indica que não, pois a sua adoção carrega o significado da negação da solidariedade social e retrocede nos direitos sociais, cuja construção é recente no Brasil. Além disso, do ponto de vista da população rural e urbana de baixa renda e dos municípios de pequeno porte, a partir dos elementos pontuados nesse artigo, fica claro que as reformas do Estado precisam levar em conta o quanto as políticas sociais implantadas no Brasil a partir da Constituição de 1988 contribuíram para a melhora da qualidade de vida e para o desenvolvimento humano em todo o país. A evolução do IDHM na região da AMAU é prova disso.

\section{CONSIDERAÇÕES FINAIS}

A análise feita aqui apontou que os benefícios previdenciários emitidos mensalmente pelo INSS (70.064 benefícios, outubro 2018), favorecem diretamente 31,26\% da população residente nos 32 municípios da AMAU. Viu-se também que os valores injetados pelo Estado brasileiro através desses benefícios, tendo como base o ano de 2018, superaram a arrecadação somada prevista pela Lei Orçamentária Anual desses mesmos municípios em 2019.

Por outro lado, as informações relativas à evolução do IDHM municipal demonstraram claramente que os municípios da região evoluíram da faixa Muito Baixo e Baixo IDHM, em 1991, para Médio, Alto e Muito Alto IDHM, em 2010 (Tabela 9). E essa evolução ocorreu nas três dimensões consideradas (Renda, Educação e Longevidade), acompanhando e até, em alguns casos, superando os índices obtidos no estado e no país. O levantamento realizado indica, portanto, que os benefícios da Previdência Social, acompanhados pelos demais investimentos sociais (nas áreas da Educação, da Saúde, da Assistência, entre outros), entre 1988 e 2018, geraram resultados importantes na melhora da qualidade de vida da população residente nessa região, especialmente para as pessoas mais pobres e para aquelas do meio rural.

Assim, fica claro, na nossa opinião, que os recursos investidos pelo Estado brasileiro na área social, especialmente os da Previdência Social, contribuem decisivamente para o desenvolvimento humano das populações residentes nos municípios, destacadamente os de menor porte. Além disso, através desses recursos, as pessoas beneficiadas consomem e 
movimentam os diversos setores da economia (o comércio, os serviços, a indústria e a agropecuária), ou seja, dinamizam os sistemas produtivos locais e, assim, estimulam o desenvolvimento (em todas as suas dimensões) das microrregiões como é o caso do Alto Uruguai rio-grandense, na qual estão localizados os 32 municípios da AMAU.

Por isso, com base nas constatações feitas, concluímos que os direitos sociais e, especialmente a Previdência, além de serem importantes para a melhora da qualidade de vida da população dessa região e para o desenvolvimento dos pequenos municípios, são relevantes também para o conjunto da população brasileira. A evolução dos índices do IDHM estadual e nacional nesse período comprovam isso.

Dessa forma, apesar dos limites desse estudo, acreditamos que os dados apresentados aqui, relativos aos municípios da AMAU, indicam que o Estado brasileiro - por meio das políticas públicas na área social - possui função fundamental para a indução do desenvolvimento do país com mais igualdade e justiça social.

\section{REFERÊNCIAS BIBLIOGRÁFICAS}

ANFIP. A Previdência Social e a Economia dos Municípios. Brasília: ANFIP, 2019, p. 178-190. Disponível em: 〈https://www.anfip.org.br>. Acesso em: 26 jun. 2019.

AVRITZER, Leonardo. O pêndulo da democracia. -1.ed. - São Paulo: Todavia, 2019.

BAUMAN, Zygmunt; BORDONI, Carlo. Estado de crise. Tradução Renato Aguiar. 1.ed.Rio de Janeiro: Zahar, 2016.

BERWANGER, Jane Lucia Wilhelm. Previdência Rural: inclusão social. -2.ed., 3. reimp. -. Curitiba: Juruá, 2011.

Brasil. Constituição da República Federativa do Brasil de 1988. Disponível em: <http://www.planalto.gov.br/ccivil_03/constituicao/constituicao.htm>. Acesso em: 22 mar. 2020 .

BRASIL. Estatísticas Municipais 2018. Secretaria da Previdência/Ministério da Economia. Disponível em: <http://www.previdencia.gov.br>. Acesso em: 18 abr. 2019. BRUM, Argemiro Jacob. Modernização da agricultura: trigo e soja. Petrópolis, RJ; Ijuí, RS: Vozes; FIDENE, 1988.

CARVALHO, José Murilo de. Cidadania no Brasil: o longo caminho. -21.ed. - Rio de Janeiro: Civilização Brasileira, 2016.

CASSOL, Ernesto (Org.); Centro de Ensino Superior de Erechim (CESE). Histórico de Erechim. Passo Fundo: Instituto Social Padre Berthier, 1979. 
CASTELLS, Manuel. Ruptura: a crise da democracia liberal. Tradução Joana Angélica d'Avila Melo. - 1.ed.- Rio de Janeiro: Zahar, 2018.

CONTAG; FETAG; STRs. Previdência Social Rural: potencialidades e desafios. Brasília, 2016. Disponível em: <http://www.contag.org.br>. Acesso em: 29 abr. 2019.

DELGADO, Guilherme. Reforma da Previdência: projeto conspira simultaneamente contra a justiça social e o equilíbrio das finanças públicas. Unisinos, São Leopoldo, mar./2019. Disponível em <http://www.ihu.unisinos.br>. Acesso em: 01 jul. 2019.

IBGE. Censo Agropecuário 2017: resultados preliminares. Rio de Janeiro: IBGE, 2018. Disponível em: <https://biblioteca.ibge.gov.br/>. Acesso em: 04 jul. 2019.

Índice de Desenvolvimento Humano Municipal Brasileiro. Brasília: PNUD, Ipea, FJP, 2013. Disponível em: <http://atlasbrasil.org.br/2013/pt/home/>. Acesso em 11 jul. 2019.

IPEA. Gastos com a Política Social: alavanca para o crescimento com distribuição de renda. Comunicados do Ipea, n. 75. Brasília, 2011.

OXFAM Brasil. País estagnado: um retrato das desigualdades brasileiras 2018. São Paulo: Brief Comunicação, 2018.

PIRAN, Nédio. Agricultura familiar: lutas e perspectivas no Alto Uruguai. Erechim: EdiFapes, 2001.

SEN, Amartya. Desenvolvimento como liberdade. Tradução Laura Teixeira Motta. São Paulo, Companhia das Letras, 2010.

TEDESCO, João Carlos; VANIN, Alex Antônio. Povoamento, aldeamento e colonização no norte do Rio Grande do Sul - século XIX: um esboço histórico para a compreensão dos atuais conflitos. In: TEDESCO, João Carlos (Org.). Conflitos Agrários no norte do Rio Grande do Sul. Porto Alegre: EST Edições, 2017, p. 37-84.

VEIGA, José Eli da. Cidades Imaginárias: o Brasil é menos urbano do que se calcula. 2.ed.- Campias, SP: Autores Associados, 2003. 